\title{
Laser Flash Photolysis of Hydrogen Peroxide to Oxidize Protein Solvent-Accessible Residues on the Microsecond Timescale
}

\author{
David M. Hambly and Michael L. Gross \\ Departments of Chemistry and Biochemistry, Washington University, St. Louis, Missouri, USA
}

\begin{abstract}
Footprinting of proteins by hydroxyl radicals generated on the millisecond to minute timescales to probe protein surfaces suffers from the uncertainty that radical reactions cause the protein to unfold, exposing residues that are protected in the native protein. To circumvent this possibility, we developed a method using a $248 \mathrm{~nm} \mathrm{KrF}$ excimer laser to cleave hydrogen peroxide at low concentrations ( $15 \mathrm{mM}, 0.04 \%)$, affording hydroxyl radicals that modify the protein in less than a microsecond. In the presence of a scavenger ( $20 \mathrm{mM}$ glutamine), the radical lifetimes decrease to $\sim 1$ microsecond, yet the reaction timescales are sufficient to provide significant oxidation of the protein. These times are arguably faster than supersecondary protein structure can unfold as a result of the modification. The radical formation step takes place in a nanoliter flow cell so that only one laser pulse irradiates each bolus of sample. The oxidation sites are located using standard analytical proteomics, requiring less than a nanomole of protein. We tested the method with apomyoglobin and observed modifications in accord with solvent accessibility data obtained from the crystal structure of holomyoglobin. Additionally, the results indicate that the F-helix is conformationally flexible in apomyoglobin, in accord with NMR results. We also find that the binding pocket is resistant to modifications, indicating that the protein pocket closes in the absence of the heme group-conclusions that cannot be drawn from current structural methods. When developed further, this method may enable the determination of protein-ligand interfaces, affinity constants, folding pathways, and regions of conformational flexibility. (J Am Soc Mass Spectrom 2005, 16, 2057-2063) (C) 2005 American Society for Mass Spectrometry
\end{abstract}

$\mathrm{M}$ ass spectrometry (MS), following the introduction of electrospray ionization (ESI) and matrix-assisted laser desorption/ionization (MALDI), has become an important means for the identification of proteins and the analytical tool of choice for proteomics. Given its sensitivity and speed, MS should also allow a more general characterization of activity, conformation, and interactions of proteins. Here we describe the development of an approach using pulsed-laser, hydroxyl-radical footprinting with product analysis by MS for determining solvent accessibility of a protein, and show early results indicating its potential utility for probing protein-ligand interfaces.

Although a protein's chemical nature is not significantly altered when it binds with a ligand, one can determine the effects of binding by evaluating changes in solvent accessibility with and without the bound ligand [1]. The use of hydroxyl radicals for this purpose is attractive because they are sufficiently small to probe solvent accessibility and are highly reactive, as has been convincingly demonstrated by successful footprinting

Published online November 2, 2005

Address reprint requests to Prof. M. L. Gross, Department of Chemistry, Washington University, One Brookings Drive, Campus Box 1134, St. Louis, MO 63130, USA. E-mail: mgross@wustl.edu of DNA/protein interactions and RNA folding [2]. Others have advanced this idea for proteins, using both continuous and pulsed sources for the radicals and MS as the analytical tool. Chance and coworkers [3] have demonstrated in an extensive set of articles a more rapid, pulsed method, in which they use synchrotron radiation to form radicals on the millisecond timescale from water molecules. Sharp et al. [4] reported photochemical oxidation by placing the protein in $5 \mathrm{M}$ hydrogen peroxide followed by 5 min irradiation with a $254 \mathrm{~nm}$ UV light source, conditions that may cause oxidation in the absence of light irradiation and induce protein unfolding. Downard [5] developed an electrical discharge source to produce radicals at atmospheric pressure within an ESI source. The synchrotron approach has been used on protein complexes of considerable size (220 kDa) [6], but uncertainty still applies to it and to other longer timescale methods. Even when exposure to radicals is conducted as fast as currently possible (7 milliseconds), protein unfolding can compete with the reactions of hydroxyl radicals [7, 8]. A clear sign that major changes in the tertiary structure can occur is the significant protein aggregation that occurs in model proteins when the pulse of ionizing radiation from the synchrotron is longer than 50 milliseconds. Thus, exposure of solvent inaccessible sites of 
the native protein may occur as a consequence of radical-induced unfolding in the super-secondary structure, giving misleading oxidations and false positive results on solvent accessibility. Furthermore, the synchrotron is hardly a routine radiation source. All other methods take significantly longer than the synchrotron method and are susceptible to the same issues.

To decrease profoundly how long the protein and radicals can react, we developed a rapid exposure approach whereby we use a pulsed $17 \mathrm{~ns} \mathrm{KrF}$ excimer laser operating at $248 \mathrm{~nm}$ to cleave hydrogen peroxide into hydroxyl radicals. Radicals are formed in nanoseconds, but they require up to 100 microseconds to self-quench. Given that this amount of time may permit some super-secondary structure unfolding, we added a radical scavenger to shorten the exposure even further. In the presence of an appropriate scavenger, the lifetime of the radicals can be less than 1 microsecond, a time scale that is nearly $10^{4}$ times shorter than current methods, arguably shorter than protein super-secondary structure unfolding, and certainly far shorter than the time for tertiary structural changes. The use of a readily available cost-effective laser makes the approach accessible to nearly all investigators. We presented a preliminary account of this work at the 2005 American Society for Mass Spectrometry conference. Presented also at the conference was a description of a similar approach using $266 \mathrm{~nm}$ irradiation of the protein in a static system but without scavenger to control the reaction duration and a 7-fold higher hydrogen peroxide concentration [9].

Another approach that uses chemical reactivity to probe protein/ligand binding is H/D amide exchange and mass spectrometry, providing complementary information on the protein backbone, not the side chains [10]. A final step in H/D exchange protocols is to quench at $\mathrm{pH}=2.5$, obviating the use of trypsin digestion and standard proteomic methods to locate the sites of solvent accessibility; use of digestion is a key step in locating the oxidation sites in any free-radical footprinting experiment.

\section{Methods}

\section{Radical Production}

A GAM Laser Inc. (Orlando, FL) 248 nm KrF excimer laser with $50 \mathrm{~mJ}$ per pulse output, combined with an external $\mathrm{B}$ and $\mathrm{K}$ Precision (Yorba Linda, $\mathrm{CA}$ ) pulse generator was used to photolyze $\mathrm{H}_{2} \mathrm{O}_{2}$ in all experiments. The laser was focused through a $250 \mathrm{~mm}$ convex lens from Edmunds Optics (Barrington, NJ) onto 100 $\mu \mathrm{m}$ i.d. fused silica tubing from Polymicro Technologies (Pheonix, AZ) located $125 \mathrm{~mm}$ from the lens. To form a UV transparent window, a propane torch was used to remove $2.5 \mathrm{~cm}$ length of polyimide coating. All chemicals were obtained from Sigma Aldrich Chemical Company (St. Louis, MO).

To label surface accessible residues, a solution of 10 $\mu \mathrm{M}$ apomyolgobin, $10 \mathrm{mM} \mathrm{NaH} \mathrm{PO}_{4}(\mathrm{pH}=7.8), 150$ $\mathrm{mM} \mathrm{NaCl}$, and $15 \mathrm{mM} \mathrm{H}_{2} \mathrm{O}_{2}$ was used $\left(\sim 0.04 \% \mathrm{H}_{2} \mathrm{O}_{2}\right)$. To this solution a scavenger was added, either glutamine or phenylalanine, to give a final scavenger concentration of $20 \mathrm{mM}$. Hydrogen peroxide was then added from a $150 \mathrm{mM} \mathrm{H} \mathrm{O}_{2}$ stock solution just before oxidation. The sample (in $50 \mu \mathrm{L}$ of solution) was loaded into a $100 \mathrm{uL}$ gas tight syringe and introduced via a syringe pump coupled to the $100 \mu \mathrm{m}$ i.d. fused silica tubing. The flow rate was set to $20 \mu \mathrm{L} / \mathrm{min}$, and the laser frequency to $15 \mathrm{~Hz}$. The capillary outflow from a sufficient number of laser shots was collected in a microcentrifuge tube, to which was added immediately $10 \mu \mathrm{L}$ of water washed agarose-immobilized catalase (to remove any remaining $\mathrm{H}_{2} \mathrm{O}_{2}$ ). After a $5 \mathrm{~min}$ incubation with gentle mixing, the beads were pelleted by centrifugation at $600 \mathrm{rpm}$, and the supernatant was removed.

Key to these experiments is the laser frequency. If the laser were fired twice on the same bolus of solution, the protein that was modified in the first shot would have had sufficient time (67 ms between each pulse) to begin unfolding and to be reoxidized, rendering suspect any derived data. A flow cell was used to minimize peroxide concentration, maximize oxidized material, and permit, considering the laser frequency, only one irradiation of fresh protein. A small intervening volume of unexposed solution was used as a diffusion barrier between an exposed bolus and the next bolus. The measured laser spot was no larger than $2.2 \mathrm{~mm}$ (theoretical width was $2 \mathrm{~mm}$ ) at the tubing, which was 100 $\mu \mathrm{m}$ i.d., and the laser pulse frequency was $15 \mathrm{~Hz}$. As the flow rate was $0.333 \mu \mathrm{L} / \mathrm{s}$, the volume of solution irradiated per pulse was $22.2 \mathrm{~nL}$, which was contained in a bolus length of $2.8 \mathrm{~mm}$. The chosen frequency ensured that $\sim 20 \%$ of the solution was unexposed to light, which agreed well with the MS observation that $\sim 20 \%$ of the protein remained unmodified.

The laser wavelength of $248 \mathrm{~nm}$ was chosen because the protein absorption at $280 \mathrm{~nm}$ extends to $260 \mathrm{~nm}$ whereas that at $190 \mathrm{~nm}$ extends to $220 \mathrm{~nm}$. Above 280 $\mathrm{nm}$, hydrogen peroxide has lower absorption, and below $190 \mathrm{~nm}$ water absorption is overwhelming.

\section{Analysis of the Oxidation Products}

Typically, $5 \mu \mathrm{L}$ (containing $50 \mathrm{pmol}$ total protein) of the collected sample was loaded onto a $\mathrm{C}_{18}$ Opti-guard column from Optimize Technologies (Oregon City, OR) that had been pre-equilibrated with $150 \mu \mathrm{L}$ of water. The sample was then loaded and desalted with $350 \mu \mathrm{L}$ of water. The protein was eluted using $20 \mu \mathrm{L} / \mathrm{min} 50 \%$ $\mathrm{CH}_{3} \mathrm{CN}$ in $0.1 \%$ formic acid into the mass spectrometer. Data acquisition was on the Waters Ultima Global quadrupole time-of-flight (Milford, MA), operating in the W mode at $\sim 15,000$ mass resolving power. The summed data were deconvoluted with MaxEnt 1 after selecting appropriate mass ranges and a "resolution" of 0.5.

The remaining protein was then digested with tryp- 
$\sin$ at a 1:20 ratio of enzyme:protein. Following a $24 \mathrm{~h}$ incubation at $37^{\circ} \mathrm{C}$, the peptides were desalted using a Millipore $\mu \mathrm{C} 18$ ZipTip (Billerica, MA). The resulting solution was lyophilized and resuspended in $10 \mu \mathrm{L}$ of solvent A $\left(97 \% \mathrm{H}_{2} \mathrm{O}, 3 \% \mathrm{CH}_{3} \mathrm{CN}, 0.1 \%\right.$ FA). $2.5 \mu \mathrm{L}$ of sample was loaded onto a silica capillary column with a PicoFrit tip (New Objective, Inc, Woburn, MA) packed in-house with $\mathrm{C} 18$ reverse-phase material $(\delta$-Pak, 0.075 $\times 100 \mathrm{~mm}, 5 \mu \mathrm{m}, 300 \AA$, Waters Corp., Milford, MA). The gradient was pumped by using an Eksigent NanoLC-1D (Livermore, CA) and was from $0 \%$ Solvent B (97\% $\left.\mathrm{CH}_{3} \mathrm{CN}, 3 \% \mathrm{H}_{2} \mathrm{O}, 0.1 \% \mathrm{FA}\right)$ to $60 \%$ Solvent B over $60 \mathrm{~min}$, then to $80 \%$ Solvent B for $10 \mathrm{~min}$ at an eluent flow of $260 \mathrm{~nL} / \mathrm{min}$ followed by a $10 \mathrm{~min}$ re-equilibration step. The flow was directed into the entrance of the heated capillary of an LTQ-FT mass spectrometer (Thermo-Electron, San Jose, CA). A mass spectrum of eluting peptides was obtained at high mass resolving power with the FT mass spectrometer component while MS/MS experiments on the nine most abundant eluents was rapidly performed in the LTQ at a collision energy of $33 \%$, selecting the precursor mass over a range of $0.5 \mathrm{Da}$ below to $2.0 \mathrm{Da}$ above and using wide-band activation. Triply repeated peaks were placed in a dynamic exclusion list for $1 \mathrm{~min}$.

The data were then searched by using Mascot (Matrix Sciences, London, UK) against the MSDB database to identify the unmodified peptides from apomyoglobin. All unmodified peptides were then manually searched for known oxidations that lead to mass modifications of $+16,+32+48,+5,-22$, and $-43 \mathrm{Da}$, adjusted according to the charge state of the precursor ion. Expected peptides that were not found were then manually searched by using the $\mathrm{m} / \mathrm{z}$ of suspected precursor ions and by considering possible missed cleavages by trypsin. This search yielded one additional peptide, but two peptides, both under $700 \mathrm{Da}$, were not found presumably because they didn't bind to the column and eluted early. Product-ion spectra of the modified peptides were then manually interpreted by comparing them with the product-ion spectra of the unmodified tryptic peptides, and an assignment was made when there was certainty that a particular residue had been modified.

\section{Results}

A control (no $\mathrm{H}_{2} \mathrm{O}_{2}$ ) analysis of apomyoglobin in sodium phosphate buffer submitted to laser irradiation indicated $\sim 5 \%$ of singly oxidized apomyoglobin, presumably from oxygen in the solution. In the presence of $15 \mathrm{mM} \mathrm{H}_{2} \mathrm{O}_{2}$ and $20 \mathrm{mM}$ phenylalanine (reaction rate with $^{\circ}$ hydroxyl ${ }^{\circ}$ radical $^{\circ}={ }^{\circ} 5^{\circ} \times{ }^{\circ} 10^{9^{\circ}} \mathrm{M}^{-1} \mathrm{~s}^{-1^{\circ}}$ [11]), ${ }^{\circ}$ we observed $^{\circ}$ virtually $^{\circ}$ no $^{\circ}$ additional $^{\circ}$ oxidation $^{\circ}\left(\right.$ Figure $\left.^{\circ} 1 \mathrm{a}\right)$, indicating that the phenylalanine, at 2000-fold excess, is capable of completely quenching the hydroxyl radicals formed by the laser. In the absence of the scavenger, we found a large amount of oxidation following laser irradiation $^{\circ}\left(\right.$ Figure $\left.^{\circ} 1 \mathrm{~b}\right) .^{\circ} \mathrm{As}^{\circ}$ these $^{\circ}$ two $^{\circ}$ cases $^{\circ}$ represent $^{-}$

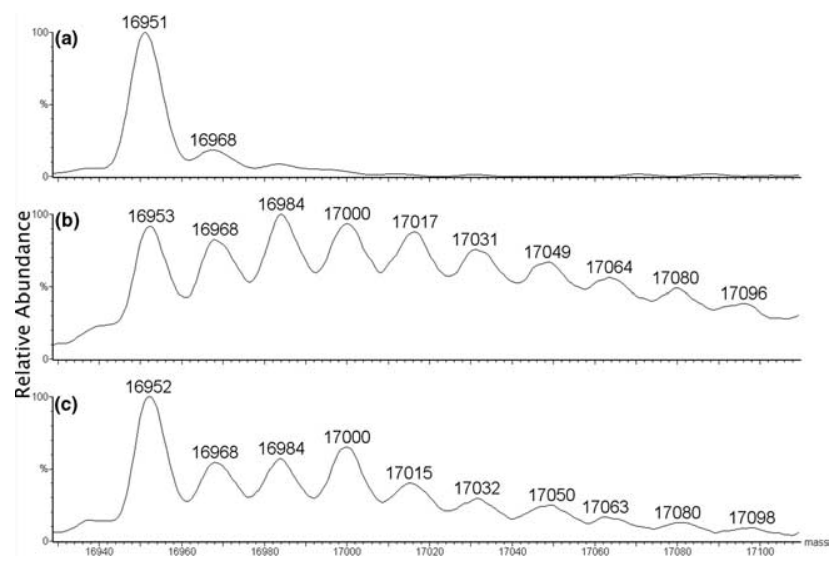

Figure 1. (a) Oxidation of $10-\mu \mathrm{M}$ apomyoglobin in $10-\mathrm{mM}$ $\mathrm{NaH}_{2} \mathrm{PO}_{4} \mathrm{pH}=7.8,15-\mathrm{mM} \mathrm{H}_{2} \mathrm{O}_{2}$ and 20-mM phenylalanine. (b) Same as (a), but no phenylalanine. (c) Same as (a) but 20-mM glutamine instead of phenylalanine.

extremes, $20 \mathrm{mM}$ glutamine was used as a moderate scavenger (reaction rate with hydroxyl radical $=5 \times$ $10^{8^{\circ}} \mathrm{M}^{-1} \mathrm{~s}^{-1^{\circ}}[12]^{\circ}$ to $^{\circ}$ give ${ }^{\circ}$ the ${ }^{\circ}$ results ${ }^{\circ}{ }^{\circ}{ }^{\circ}$ Figure ${ }^{\circ}$ c. The The ${ }^{\circ}$ use of glutamine afforded reasonable amounts of oxidation that should limit the number of modifications to those residues that are highly reactive and solvent-exposed. Thus, only if a residue is exposed and reactive, will we observe oxidation. If a ligand is included with a fresh sample for oxidation, only those residues that are still exposed and reactive will be modified. A comparison of the two datasets will enable a binary readout; for example, residue 73 is exposed with and without the ligand whereas residue 83 is buried by the ligand and is oxidized only in the apo form. Some caution is advised because the protein fold can be stabilized by ligand binding, covering distant sites owing to allosteric rearrangements. According to published data on the reaction rates of hydroxyl radicals from the Radiation Chemistry Data Center of the Notre Dame Radiation Laboratory, we anticipate the most reactive residues to be Cys, Met, Trp, Tyr, Phe, His, Arg, Leu, Ile. We did not observe oxidation of arginine and anticipate that trypsin would have trouble cutting at an arginine in the absence of its guanido group (a loss of 43 Da is typically observed ${ }^{\circ}$ upon $^{\circ}$ oxidation $^{\circ}[13] . .^{\circ}$ Most $^{\circ}$ residues $^{\circ}$ undergo addition of oxygen as the final product of the reaction. However, ${ }^{\circ}$ histidine ${ }^{\circ}$ has $^{\circ}$ five $^{\circ}$ possible $^{\circ}$ products $^{\circ}[13]$, showing losses of $22 \mathrm{Da}$ and gains of $5 \mathrm{Da}$. We did observe a minor -10 Da product as previously reported, but the $+16 \mathrm{Da}$ and $-23 \mathrm{Da}$ products were not observed.

\section{Timescale of Reaction}

At this point, we have demonstrated three experimental outcomes: (1) a 17 ns pulsed $248 \mathrm{~nm}$ laser can generate hydroxyl radicals from a low concentration of hydrogen peroxide, (2) the radicals can be efficiently quenched by a known radical scavenger, and (3) in the absence of a 
quencher, apomyoglobin is heavily oxidized. We have not, however, addressed the time scale of the reaction. To do so, we calculated the kinetics of a pseudo first-order reaction between hydroxyl radicals and glutamine. We first used $20 \mathrm{mM}$ phenylalanine as a dosimeter, and no oxidation products of phenylalanine were observed (data not shown). This is likely due to the limited dynamic range of the instrument used to investigate phenylalanine oxidation; thus, we estimate that the maximum concentration of hydroxyl radicals is 1 $\mathrm{mM}$. Even if this many radicals were produced, many rapidly self-quench reforming $\mathrm{H}_{2} \mathrm{O}_{2}$, given that the reaction rate constant for self quenching is $6 \times 10^{9}$ $\mathrm{M}^{-1} \mathrm{~s}^{-1^{\circ}}[11],$. Thus, $^{\circ}{ }^{\circ} 20^{\circ} \mathrm{mM}^{\circ}$ concentration ${ }^{\circ}$ of ${ }^{\circ}$ scavenger is a large excess with respect to the radicals, permitting use of pseudo-first-order kinetics. Using the known rate constants for reactions of phenylalanine or glutamine with the hydroxyl radical and assuming a maximum starting concentration of $1 \mathrm{mM}$ radical, we calculated the time profile of hydroxyl radical concentration in the solution'(Figure 2). In the absence of ${ }^{\circ}{ }^{\circ}$ scavenger, ${ }^{\circ}$ we ${ }^{\circ}$ used second-order kinetics to compute the self-quenching, demonstrating that the radical exists at significant concentrations relative to the protein even after $100 \mu \mathrm{s}$. This is remedied by using a scavenger to remove the radicals from the reaction medium in a more rapid manner. Whereas global tertiary changes will likely not occur in $100 \mu \mathrm{s}$, changes in the organization of secondary structure are possible.

Kinetic analysis reveals that, in the presence of 20 $\mathrm{mM}$ phenylalanine, no hydroxyl radicals remain in solution after $70 \mathrm{~ns}$, whereas with $20 \mathrm{mM}$ glutamine, the radicals are gone in slightly under $1 \mu \mathrm{s}$. This comparison indicates that the reaction duration and protein exposure to the radicals can be tuned using scavengers that react with $\mathrm{OH}$ radicals with different reaction rate constants.

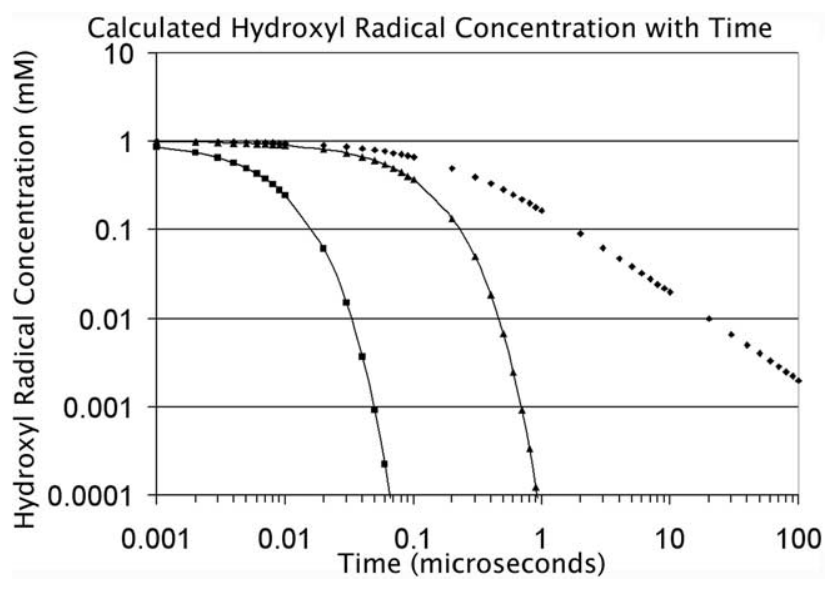

Figure 2. Diamond with no line: the second-order disappearance of hydroxyl radical as a result of self-reaction to form $\mathrm{H}_{2} \mathrm{O}_{2}$. Square: the first-order disappearance of hydroxyl radical as a result of reaction with excess phenylalanine $(20 \mathrm{mM})$. Triangle: the first-order disappearance of hydroxyl radical as a result of reaction with excess glutamine ( $20 \mathrm{mM})$.

\section{Comparison with Timescale of Protein Unfolding}

Does the protein unfold under these reaction conditions? Although it has been known for years that some small proteins can undergo complete global unfolding in times as short as low microseconds, depending on the ${ }^{\circ}$ size $^{\circ}[8],{ }^{\circ} \mathrm{we}^{\circ}$ are $^{\circ}$ concerned that changes in the supersecondary structure can occur more rapidly. Indeed, recent advances in laser-induced temperature jump experiments, accompanied by IR laser monitoring of solvated or buried helical unfolding, demonstrate that solvated $\alpha$-helices can fold ${ }^{\circ}{ }^{\circ}{ }^{\circ}$ tens ${ }^{\circ}$ of nanoseconds [14을.

For ${ }^{\circ}$ apomyoglobin, ${ }^{\circ}$ the ${ }^{\circ}$ folding/ unfolding ${ }^{\circ}$ is a twostate process, $\mathrm{F} \rightleftarrows \mathrm{U}$, where $\mathrm{F}$ is the folded and $\mathrm{U}$ the unfolded states. Folding to give the native state occurs in two steps, the first is fast helix formation (folding lifetime in the range of 48-200 ns) followed by a slower establishment ${ }^{\circ}$ of $^{\circ}$ tertiary ${ }^{\circ}$ interactions ${ }^{\circ}$ and the ${ }^{\circ}$ exclusion of $^{\circ}$ water (folding ${ }^{\circ}$ lifetime ${ }^{\circ}$ of $\left.^{\circ} \sim 130^{\circ} \mu \mathrm{s}\right)^{\circ}[14] .{ }^{\circ}$ Given $^{\circ}$ the single, two-stage kinetics, the first step in unfolding is the breaking of tertiary interactions and admitting water. This process has a relaxation time of $\sim 200 \mu \mathrm{s}$, which is considerably slower than the disappearance time for the $\mathrm{OH}$ radicals in the scavenger-controlled experiment we performed.

Although it is not possible to generalize about protein folding (unfolding) as rates vary from protein to protein or to assume that folding and unfolding of proteins are microscopically reversible, it is instructive to consider the rate of unfolding for one of the fastest folding ${ }^{\circ}$ proteins, ${ }^{\circ} \mathrm{B}-$ domain $^{\circ}$ of $^{\circ}$ staphylococcal ${ }^{\circ}$ protein ${ }^{\circ} \mathrm{A}$ $(\mathrm{BdpA})^{\circ}[16] .{ }^{\circ}$ Laser-induced ${ }^{\circ}$ temperature jump coupled with fast IR suggest again that the first step in folding is formation of individual helices ( 100 ns) followed by a slower movement together of the helices with exclusion of water $(\sim 10 \mu \mathrm{s})$. Generally speaking, the disappearance of radicals in this experiment $(\sim 1 \mu \mathrm{s})$ is faster than the time for the second step in unfolding $(\sim 10 \mu \mathrm{s})$ that re-admits water (and $\mathrm{OH}$ radicals in our experiment).

Of course, these unfolding times are determined by temperature jump, which does not apply to our experiments. We are concerned with unfolding that occurs as a result of oxidation. But if the admission of water accompanying unfolding does not occur any faster than tens of microseconds, even for fast folding proteins, then the sites exposed in the unfolding cannot be significantly modified by $\mathrm{OH}$ radicals contained in the water and produced by the laser pulse under our experimental conditions.

\section{Location of Sites of Oxidation}

We then used trypsin to digest the glutamine-scavenged sample and analyzed the mixture of peptides with LC/MS/MS. Owing to the complexity of the data, we examined only the MASCOT-identified precursor ions (unoxidized peptides) for known oxidations by comparing the product-ion spectrum of a selected precursor 
Table 1. Residues, position number, side-chain solvent exposure and observed oxidations as ordered by residue reactivity $(\operatorname{Trp}>$ Tyr $>$ Met $>$ Phe $>$ His). Solvent exposure values in parantheses are for residues located in the core of the hydrophobic pocket and may not be solvent exposed

\begin{tabular}{|c|c|c|c|}
\hline Type & A.A.\# & $\begin{array}{c}\text { Solvent } \\
\text { Exposure }\left(A^{2}\right)\end{array}$ & Oxidized \\
\hline TRP & 7 & 17 & $Y$ \\
\hline TRP & 14 & 14 & $\mathrm{Y}$ \\
\hline TYR & 103 & 20 & $\mathrm{Y}$ \\
\hline TYR & 146 & 12 & $\mathrm{Y}$ \\
\hline MET & 55 & 11 & $\mathrm{Y}$ \\
\hline MET & 131 & 5 & $Y$ \\
\hline PHE & 33 & 2 & \\
\hline PHE & 43 & 62 & $\mathrm{Y}$ \\
\hline PHE & 46 & 4 & \\
\hline PHE & 106 & 33 & $\mathrm{Y}$ \\
\hline PHE & 123 & 7 & \\
\hline PHE & 138 & (32) & \\
\hline PHE & 151 & 34 & $\mathrm{Y}$ \\
\hline HIS & 24 & 11 & $\mathrm{Y}$ \\
\hline HIS & 36 & 37 & $\mathrm{Y}$ \\
\hline HIS & 48 & 90 & Y \\
\hline HIS & 64 & 36 & Y \\
\hline HIS & 81 & 104 & $Y$ \\
\hline HIS & 82 & 8 & \\
\hline HIS & 93 & 37 & $\mathrm{Y}$ \\
\hline HIS & 97 & 50 & n.d. \\
\hline HIS & 113 & 61 & $\mathrm{Y}$ \\
\hline HIS & 116 & 60 & $\mathrm{Y}$ \\
\hline HIS & 119 & 27 & $\mathrm{Y}$ \\
\hline
\end{tabular}

A peptide that did not bind the HPLC column is annotated with n.d.

ion and of a selected oxidized precursor ion and manually interpreted the results. From these comparisons we generated a list of observed modifications to highly reactive ${ }^{\circ}$ residues $^{\circ}\left(\right.$ Table $\left.^{\circ} 1\right)$. ${ }^{\circ}$ Because ${ }^{\circ}$ there ${ }^{\circ}$ is $^{\circ}{ }^{\circ}{ }^{\circ} \mathrm{X}$-ray ${ }^{\circ}$ or NMR structure of apomyoglobin, owing to conformational heterogeneity, the solvent accessibility data in Table $1{ }^{\circ}$ was ${ }^{\circ}$ obtained ${ }^{\circ}$ from ${ }^{\circ}$ GetArea 1.1 by $^{\circ}$ summing the solvent accessibility of each atom along the side-chain, including $\mathrm{C} \alpha$, using the pdb file 1WLA of wild type horse heart holomyoglobin obtained by X-ray crystallography. This program does not recognize the heme group; thus, the cavity appears open as if the heme were absent. We expect water penetration into the binding pocket if the protein is a rigid "lock and key" in the absence of the heme. The NMR C $\alpha$ backbone measurements of apomyoglobin show that the F-helix residues from 83 to 100 have no measurable signal $[17]^{\circ}{ }^{\circ}$ indicating ${ }^{\circ}$ that $^{\circ}$ these ${ }^{\circ}$ residues $^{\circ}$ are $^{\circ}$ sampling different conformations on the sub-millisecond time scale.

All but one oxidized peptide that underwent fragmentation gave sufficient $\mathrm{b}$ and $\mathrm{y}$ ions to locate the modification with certainty. In this one case, the oxidation of an exposed proline (P37) is probable, although we could not positively differentiate the proline from an adjacent exposed glutamate. This modification was not annotated on the sequence, although both amino acid residues are solvent exposed.
Describing the outcome in general terms, we found that methionine and tryptophan were oxidized even when only a small amount of their side-chain was solvent exposed. Tyrosine and phenylalanine side chains with over $20 \AA^{2}$ solvent exposure also underwent oxidation (the sole exception, Phe 138, is discussed below). All histidine residues were modified, with the exception of His 82, which has less than $10 \AA^{2}$ solvent exposure. Leucine and isoleucine residues were far more discriminatory, requiring nearly full solvent exposure to be modified. We observed oxidations on isoleucine 21 with $71 \AA^{2}$ of solvent exposure while Ile 101 with $63 \AA^{2}$ of solvent exposure was on a peptide that did not bind to the column. Leucine 89 and 137 with $51 \AA^{2}$ and $50 \AA^{2}$ of solvent exposure, respectively, were both oxidized. Leucine 149 at $60 \AA^{2}$ of solvent exposure was not oxidized, but it is located between a phenylalanine and a tyrosine, both of which are oxidized and more reactive towards hydroxyl radicals than is leucine. All other leucine and isoleucine residues were not oxidized, and have less than $50 \AA^{2}$ of solvent exposure.

Leu 86 is an exception with only $4 \AA^{2}$ of solvent exposure, but its oxidation correlates extremely well with $^{\circ}$ data $^{\circ}$ from $^{\circ}$ Eliezer $^{\circ}$ and $^{\circ}$ Wright $^{\circ}[17],{ }^{\circ}$ who ${ }^{\circ}$ demonstrate that this region is conformationally flexible. The oxidation data prove that the region must be highly solvent accessible as there are three oxidations.

To indicate the quality of the data and validity of the reasoning, ${ }^{\circ}$ we $^{\circ}$ present $^{\circ}$ Figure $^{\circ} 3{ }^{\circ}$ which ${ }^{\circ}$ shows ${ }^{\circ}$ the MS/MS data indicating oxidation at Leu 137 but not Phe 138 from MS/MS analysis of the peptide ALELFR. The basis for this conclusion is the $\mathrm{y}_{2}$ ion $\left(\mathrm{FR}^{+}\right)$at $\mathrm{m} / \mathrm{z}$ 322 produced from both the modified and unmodified peptides. The shift of $\mathrm{y}_{3}$ by $+16\left(\mathrm{LFR}^{+}\right)$indicates that the leucine is modified. This demonstrates the method's ability to locate solvent-accessible residues considering that ${ }^{\circ} \mathrm{a}^{\circ}$ leucine ${ }^{\circ}$ residue $^{\circ}\left(1.5^{\circ} \times{ }^{\circ} 10^{9^{\circ}} \mathrm{M}^{-1} \mathrm{~s}^{-1^{\circ}}[18]\right)^{\circ}$ is ${ }^{\circ} \sim 4$ times less reactive than a phenylalanine $\left(6.5 \times 10^{9}\right.$ $\mathrm{M}^{-1} \mathrm{~s}^{-1^{\circ}}[11]^{\circ}$ residue. ${ }^{\circ}$ Additionally, ${ }^{\circ}$ recent ${ }^{\circ}$ unpublished data from our laboratory indicate that with a continuous beam exposure for 30 seconds, $C D$ measurements show protein unfolding, and in these experiments, we observe oxidation of Phe 138.

Our data indicate that the heme binding pocket is partially closed in the absence of the heme. His 97, His 64, Tyr 103, and Phe 43, all residues within $7 \AA$ of the heme, are solvent accessible in the presence of the heme and are oxidized in the apo form by our procedure. Phe 138 , however, is completely occluded by the heme and would become fully exposed when the heme is absent if the pocket does not close. Yet, this residue shows no detectable oxidation. Thus, Phe 138 must not be exposed to the solvent while the histidine residues at the mouth of the pocket are oxidized, indicating partial closure of the binding pocket in the absence of heme. Given the hydrophobic nature of the pocket, it is reasonable that a decrease in enthalpy would cause the pocket to close rather than remain open by paying 


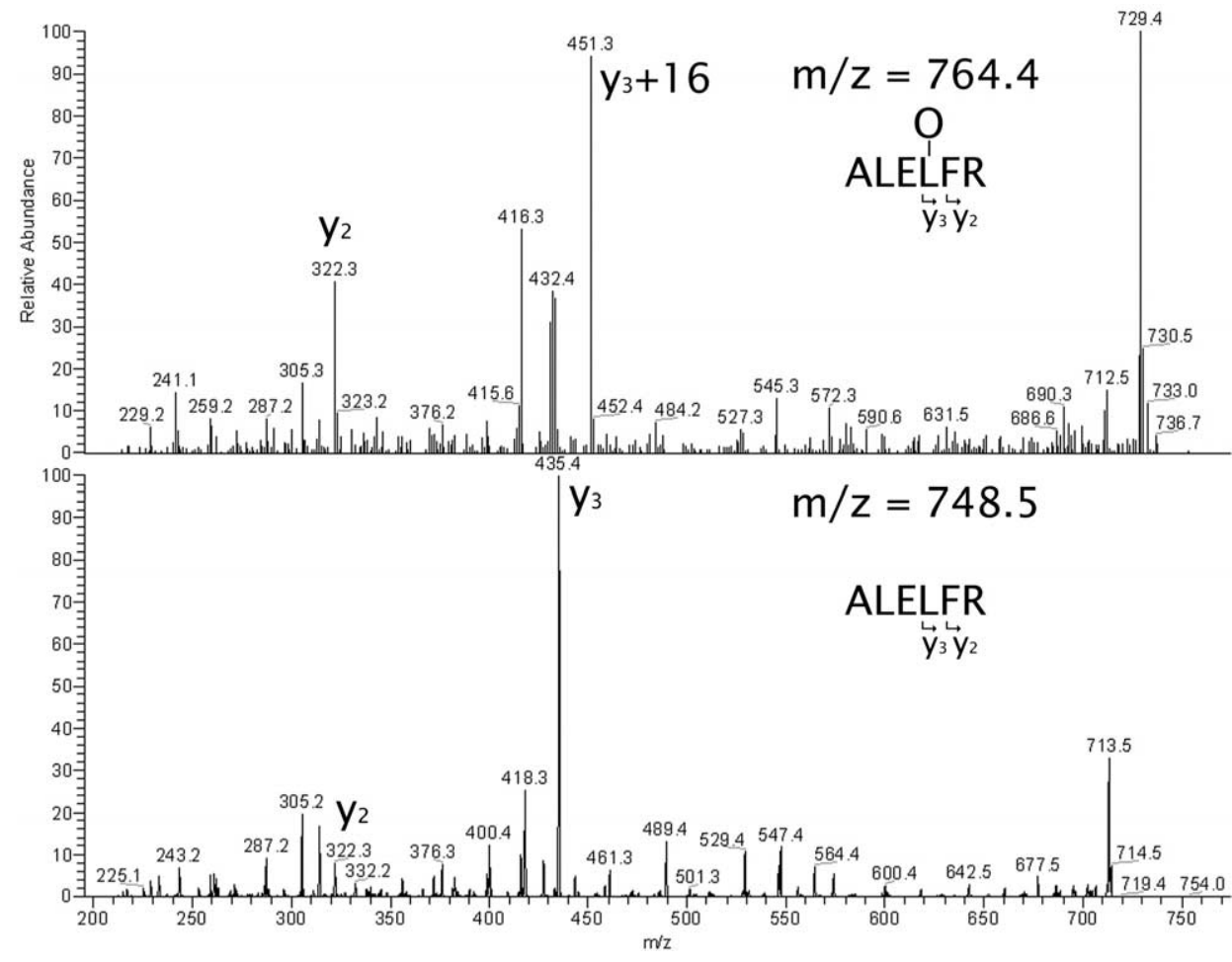

Figure 3. Top, MSMS fragmentation pattern of $[\mathrm{M}+\mathrm{H}]^{+}$oxidized ALELFR. Bottom, MSMS fragmentation pattern of $[\mathrm{M}+\mathrm{H}]^{+}$of $m / z 748.5$, identified by MASCOT as ALELFR. The modification is observed on the second leucine. The ion of $m / z 713$ or 729 is presumably formed by loss of water as a result of wide-band activation followed by loss of ammonia.

the significant entropic penalty of ordering water molecules to fill the cavity. The entrance of the pocket, however, is where the three histidine residues are located, and they are expected to be solvent accessible.

Of 50 possible oxidations sites, we observe oxidations at 23; previous publications report only nine. Notably, we observe oxidation on most of the vulnerable sites along the $\mathrm{F}$ helix, a region that is disordered by the absence of a $C \alpha$ NMR signal. Disorder is observed from residue 81 to 100 in sperm whale apomyoglobin, although a similar chemical shift is observed at residue 81 and 82 when comparing the holo and apo forms. We could not determine whether His 97 can be oxidized, owing to the inability to retain in the HPLC step the small tryptic peptide that contains this residue.

\section{Conclusions}

This approach to protein footprinting is capable of modifying a native protein on the microsecond timescale with sufficient yield to permit MS/MS analysis to identify the solvent-exposed and subsequently modified residues. We chose bottom-up sequencing, but the method could also employ top-down sequencing by electron ${ }^{\circ}$ capture $^{\circ}$ with $^{\circ} \mathrm{FT}^{\circ}$ mass $^{\circ}$ spectrometry ${ }^{\circ}[19] .^{\circ}{ }^{\circ}$ To understand further the approach, we are undertaking studies to quantify the amount of hydroxyl radical formed in the laser pulse, to use a fluorescence dosim- eter to demonstrate the actual duration of reaction, and to test the method with other protein models. Valuable uses of this approach would be the determinations of affinity constants for protein-ligand interactions and of protein/protein interfaces. The latter capability may afford a high-throughput method in drug discovery by targeting protein-protein interactions in the absence of a readily assayable protein activity by searching for ligands that produce oxidations at the protein interface.

\section{Acknowledgments}

This research was supported by the National Centers for Research Resources of the NIH (grant P41RR00954) and by a supplemental grant from that Center. The authors thank Drs. H. Rohrs, I. Vidavsky, and J. Walters for their help in data collection and analysis.

\section{References}

1. Zhu, M. M.; Rempel, D. L.; Du, Z.; Gross, M. L. Quantification of Protein-Ligand Interactions by Mass Spectrometry, Titration, and H/D Exchange: PLIMSTEX. J. Am. Chem. Soc. 2003, 125, 5252-5253.

2. Maleknia, S. D.; Ralston, C. Y.; Brenowitz, M. D.; Downard, K. M.; Chance, M. R. Determination of Macromolecular Folding and Structure by Synchrotron X-Ray Radiolysis Techniques. Anal. Biochem. 2001, 289, 103-115.

3. Kiselar, J. G.; Maleknia, S. D.; Sullivan, M.; Downard, K. M.; Chance, M. R. Hydroxyl Radical Probe of Protein Surfaces 
Using Synchrotron X-Ray Radiolysis and Mass Spectrometry. Int. J. Radiat. Biol. 2002, 78, 101-114.

4. Sharp, J. S.; Becker, J. M.; Hettich, R. L. Analysis of Protein Solvent Accessible Surfaces by Photochemical Oxidation and Mass Spectrometry. Anal. Chem. 2004, 76, 672-683.

5. Maleknia, S. D.; Chance, M. R.; Downard, K. M. ElectrosprayAssisted Modification of Proteins: A Radical Probe of Protein Structure. Rapid Commun. Mass Spectrom. 1999, 13, 2352-2358.

6. Guan, J.-Q.; Takamoto, K.; Almo, S. C.; Reisler, E.; Chance, M. R. Structure and Dynamics of the Actin Filament. Biochemistry 2005, 44, 3166-3175.

7. Maleknia, S. D.; Wong, J. W. H.; Downard, K. M. Photochemical and Electrophysical Production of Radicals on Millisecond Timescales to Probe the Structure, Dynamics, and Interactions of Proteins. Photochem. Photobiol. Sci. 2004, 3, 741-748.

8. Naganathan, A. N.; Munoz, V. Scaling of Folding Times with Protein Size. J. Am. Chem. Soc. 2005, 127, 480-481.

9. Aye, T. T.; Low, T. Y.; Sze, S. K. Nanosecond Laser-Induced Photochemical Oxidation Method for Protein Surface Mapping with Mass Spectrometry. Anal. Chem. 2005, 77, 58145822.

10. Smith,, D. L., Dharmasiri,, K. Protein-Ligand Binding Studied by Amide Hydrogen Exchange and Mass Spectrometry. NATO ASI Ser. C 1998, 510, 45-58.

11. Buxton, G. V.; Greenstock, C. L.; Helman, W. P.; Ross, A. B. Critical Review of Rate Constants for Reactions of Hydrated Electrons, Hydrogen Atoms, and Hydroxyl Radicals (.OH/ .O-) in Aqueous Solution. J. Phys. Chem. Ref. Data 1988, 17, 513-886.
12. Masuda, T.; Nakano, S.; Kondo, M. Rate Constants for the Reactions of $\mathrm{OH}$ Radicals with the Enzyme Proteins as Determined by the p-Nitrosodimethylaniline Method. J. Radiat. Res. (Tokyo) 1973, 14, 339-345.

13. Xu, G.; Takamoto, K.; Chance, M. R. Radiolytic Modification of Basic Amino Acid Residues in Peptides: Probes for Examining Protein-Protein Interactions. Anal. Chem. 2003, 75, 6995-7007.

14. Gilmanshin, R.; Williams, S.; Callender, R. H.; Woodruff, W. H.; Dyer, R. B. Fast Events in Protein Folding: Relaxation Dynamics of Secondary and Tertiary Structure in Native Apomyoglobin. Proc. Natl. Acad. Sci. U.S.A. 1997, 94, 37093713.

15. Williams, S.; Causgrove, T. P.; Gilmanshin, R.; Fang, K. S.; Callender, R. H.; Woodruff, W. H.; Dyer, R. B. Fast Events in Protein Folding: Helix Melting and Formation in a Small Peptide. Biochemistry 1996, 35, 691-697.

16. Vu, D. M.; Myers, J. K.; Oas, T. G.; Dyer, R. B. Probing the Folding and Unfolding Dynamics of Secondary and Tertiary Structures in a Three-Helix Bundle Protein. Biochemistry 2004, 43, 3582-3589.

17. Eliezer, D.; Wright, P. E. Is Apomyoglobin a Molten Globule? Structural Characterization by NMR. J. Mol. Biol. 1996, 263, 531-853.

18. Scholes, G.; Shaw, P.; Willson, R. L.; Ebert, M. In Pulse Radiolysis, Ebert, M.; Keene, J. P.; Swallow, A. J.; Baxendale, J. H., Eds; Academic Press: New York, 1965; pp. 151-164.

19. Ge, Y.; Lawhorn, B. G.; ElNaggar, M.; Sze, S. K.; Begley, T. P.; McLafferty, F. W. Detection of Four Oxidation Sites in Viral Prolyl-4-Hydroxylase by Top-Down Mass Spectrometry. Protein Sci. 2003, 12, 2320-2326. 